\title{
Comparison of Preoperative and Postoperative Nose Scores in Septal Deviation
}

\section{IJCRR}

Section: Healthcare

ISI Impact Factor

(2019-20): 1.628

IC Value (2019): 90.81

$\operatorname{SJIF}(2020)=7.893$

\section{R. M. Bala Ashwathy ${ }^{1}$, B. C. Surekha*2}

'Undergraduate, 3rd Year M.B.B.S., Saveetha Medical College and Hospital, Thandalam, Chennai - 602 105, India; ${ }^{A}$ Assistant Professor, Department of ENT, Saveetha Medical College and Hospital, Thandalam, Chennai - 602 105, India.

\section{ABSTRACT}

Introduction: Deviated nasal septum (DNS) is a common condition, mainly causing nasal obstruction in a person. It is usually asymptomatic but may cause interference in daily life in some. Hence symptomatic DNS patients undergo septoplasty. Septoplasty is a conservative surgical procedure, correcting the deviated parts of nasal septum. Some patients have persistent symptoms even after septoplasty. NOSE (Nasal Obstruction Symptom Evaluation) scale was used as a tool to measure nasal obstruction and evaluate the outcomes of septoplasty, in DNS patients.

Aim of the Study: To compare the NOSE scores before and after conducting septoplasty in DNS patients and evaluate the effectiveness of septoplasty.

Material and Methods: A prospective study was conducted in a tertiary care hospital in DNS patients undergoing septoplasty. NOSE scores were obtained preoperatively and postoperatively from them and analyzed.

Results: A total of 20 patients were included in the study, for a period of 2 months from January 1, 2020 to February $28,2020$. Both male and female were included in the study. The mean age of the patients was 37.2 years. The preoperative NOSE scores showed mild obstruction in $2(10 \%)$, moderate obstruction in $11(55 \%)$ and severe obstruction in $7(35 \%)$. The postoperative NOSE scores showed persistent nasal obstruction in $1(5 \%)$ patient. The mean and SD of preoperative NOSE score was 47.25 and 19.83 respectively. The mean and SD of postoperative NOSE score was 0.25 and 1.11 respectively $(P<0.001)$. The postoperative NOSE scores were less than the preoperative NOSE scores.

Conclusion: Each patient showed improvement in nasal symptoms after proper treatment and septoplasty was found to be effective in $95 \%$ of the patients.

Key Words: Deviated nasal septum, NOSE scale, Septoplasty, Nasal obstruction, Septal correction, Birth trauma

\section{INTRODUCTION}

Septal deviation is a condition characterized by deviation or displacement of nasal septum. It is called deviated nasal septum (DNS). There are different types of DNS like anterior dislocation, C-shaped deformity, S-shaped deformity, spurs and thickening ${ }^{1-3}$. It is commonly caused by trauma and developmental abnormality. Traumatic incidents in childhood or those inflicted during labour in vaginal birth can cause the development of DNS in later stages of life ${ }^{1-4}$. A frontal or lateral blow in accidents is also commonly seen in DNS. Developmental errors information of nasal septum, abnormal intrauterine postures compressing the nose, conditions like cleft palate are commonly seen. In later stages of life, mouth breathers like hypertrophy and nasal polyp or tumours cause DNS. Some degrees of racial and hereditary factors also play a role ${ }^{5}$. The deviated nasal septum may be asymptomatic but some patients usually present with the complaint of nasal obstruction most commonly, followed by headache, external deformity, anosmia, etc. Sometimes untreated DNS can lead to complications like sinusitis, middle ear infections, etc ${ }^{7}$. The definitive treatment is universally accepted as surgical correction or 'septoplasty'. However, the benefits of septoplasty, as perceived by the patient, widely vary over different grades of satisfaction, ranging from complete alleviation of symptoms to total failure. Pre and post-operative assessments of

\section{Corresponding Author:}

Dr. B. C. Surekha, B36, Arcot terrace, No 160, Arcot Road, Vadapalani, Chennai - 600 026, India.

Contact: +91-9441840073; Email: drbcsurekha@gmail.com

ISSN: 2231-2196 (Print)

Received: 11.01 .2021
ISSN: 0975-5241 (Online)

Revised: 02.02 .2021
Accepted: 13.03 .2021
Published: 30.08 .2021 
symptoms are necessary for outcome analysis. Hence septoplasty, conservative surgical management, where most deviated parts are removed and septal framework is corrected and repositioned, is done for DNS. But it is usually avoided in children unless it is very severe. Though septoplasty is conducted as a common procedure some patients may have persistent symptoms. There are many questionnaires available; some of them only contain items related to nasal symptoms whereas others also include general quality of life items. We want to focus on the surgical results per se and would therefore prefer a questionnaire that specifically assesses nasal symptoms. The Nasal Obstruction Symptom Evaluation (NOSE) questionnaire ${ }^{8-10}$ has been validated and used in many countries, but one item is difficult to translate into the Norwegian language.

Questionnaires using a single visual analogue scale (VAS) for obstruction have been used in several studies ${ }^{11}$. We believe that the use of separate and continuous scales for obstruction in different situations (day, night, and during exercise) will yield clinically relevant information about the patient's symptoms and how they change in response to surgery. Other nasal symptoms and the use of nasal medication should also be taken into account in surveying the results. As a patient's perception of nasal airflow is of primary concern, the improvement in subjective score of patient's symptoms is an important outcome parameter of the management plan to address the complex problem. This is a disease-specific quality of life instrument for subjective assessment of nasal obstruction. It is in a form of a questionnaire containing five symptoms in increasing severity. The results of septoplasty are thereby evaluated using the NOSE (Nasal Obstruction Symptom Evaluation) scale, to observe and record the improvement seen before and after patients undergoing septoplasty. This comparison of preoperative and postoperative NOSE scores will reveal the efficiency of septoplasty in the deviated nasal septum.

\section{AIM AND OBJECTIVES}

- To analyze the changes in the NOSE survey, before and after conducting septoplasty in DNS patients.

- To assess the specific improvement in patients following septoplasty.

- To evaluate the outcomes of septoplasty.

\section{MATERIAL AND METHODS}

A prospective study with the Ethical committee approval number SMC/IEC/2020/03/317 was conducted in a tertiary care hospital. A total of 20 patients with nasal septal deviation, posted for septoplasty in the ENT department, were analyzed in this study, for two months, from $1^{\text {st }}$ January 2020 to $28^{\text {th }}$ February 2020. Written informed consent was obtained from all patients. The study was based on the NOSE (Nasal Obstruction Symptom Evaluation) scale. All the patients with symptoms of nasal congestion, nasal obstruction, trouble breathing through the nose, trouble to sleep and trouble while exercise, who came to the ENT department were included in the study. The NOSE scores were obtained preoperatively and postoperatively 2 weeks after septoplasty. The NOSE scale was obtained from each patient. The preoperative and postoperative NOSE scores were recorded, totalled and compared for each patient and changes were assessed and the outcome of septoplasty was evaluated including demographic analysis.

\section{Inclusion Criteria}

- All patients between 20 years and 65 years of age were included in the study.

- All patients with symptoms of nasal congestion, nasal obstruction, trouble breathing through the nose, trouble sleeping, trouble while exercise or exertion was included in the study. ${ }^{12}$

\section{Exclusion Criteria}

- Patients less than 20 years and more than 65 years of age were excluded from the study

- Patients with a nasal polyp, allergic rhinitis and fracture of the septum or nasal bone were excluded from the study. ${ }^{13}$

\section{STATISTICAL METHODS}

Continuous data were represented as mean $\pm \mathrm{SD}$. Categorical data were represented as value $(\%)$. Paired t-test was the statistical tool used in the study. Data were analyzed with SPSS software (version 22.0 for Windows, IBM Corp., Armonk, NY). A P-value less than 0.05 was considered statistically significant.

\section{RESULTS}

A total of 20 patients were in this study. Demographic details were analyzed for each subject. Among them 15 (75\%) were male and $5(25 \%)$ were female. The mean age was 37.2 years with a range, 20-62 years. The age-wise and gender-wise distribution of the study subjects is given in Figure 1.

All the 20 patients, undergoing septoplasty, were evaluated based on the NOSE (Nasal Obstruction Symptom Evaluation) scale. The NOSE scale covers mainly five symptoms, namely, nasal congestion/stuffiness, nasal blockage/obstruction, trouble breathing through the nose, trouble sleep, unable to get enough air through the nose while exercise or exerting. The scale grades each symptom in the increasing order of severity. The NOSE scale used in this study is 
shown in Table 1 . The survey was conducted preoperatively first and postoperatively, 2 weeks after the surgery. The patients graded the severity of the symptoms from 0 to 4 . 0 - no problem, 1 - very mild, 2 - moderate, 3 - fairly bad, 4 - severe, as given in Table 1 . The values were summed to 20 . The mean and SD of the preoperative NOSE score was 9.45 and 3.96. The mean and SD of postoperative NOSE score was 0.05 and $0.22(\mathrm{P}<0.001)$. The results were graded on a scale of 100 and then compared.

They were divided into 3 categories - mild obstruction $(<25)$, moderate obstruction $(25-50)$ and severe obstruction $(>50)$. This has been illustrated in Figure 2. Among the 20 patients, preoperative NOSE scores showed mild obstruction in $2(10 \%)$, moderate obstruction in $11(55 \%)$ and severe obstruction in $7(35 \%)$. On grading to 100 , the mean and SD of the preoperative score was 47.25 and 19.83. Postoperative NOSE score shows mild obstruction in only $1(5 \%)$, among the 20 patients. The mean and SD of the postoperative score was 0.25 and 1.11. $(\mathrm{P}<0.001)$

The age-wise distribution concerning the symptoms is given in Table 2. Among the age group 20-29 years, nasal congestion was seen in $9(45 \%)$, nasal obstruction in $9(45 \%)$, trouble to breathe in $8(40 \%)$, trouble to sleep in $7(35 \%)$ and trouble during exercise in $5(25 \%)$. In 30-39 years, $4(20 \%)$ showed nasal congestion, $2(10 \%)$ with nasal obstruction, $1(5 \%)$ with trouble breathing, $4(20 \%)$ with trouble sleeping and $2(10 \%)$ with trouble while exercising. In the age group 40-49 years and $\geq 50$ years, all patients showed all five symptoms.

The gender-wise distribution concerning symptoms is given in Table 3. In the male gender, all showed nasal congestion, nasal obstruction and trouble breathing. Trouble to sleep was seen in $13(86 \%)$ and trouble while exercising in $11(73 \%)$. Among the female patients, $3(60 \%)$ had nasal obstruction, $1(20 \%)$ had trouble to breathe and $3(60 \%)$ had trouble while exercise and exerting. All of them had nasal congestion and trouble sleeping.

On analysis, significant changes were noted in the NOSE score. A comparison of preoperative and postoperative NOSE scores is given in Figure 3. The postoperative NOSE scores, after conducting septoplasty, was comparatively less than the preoperative NOSE scores $(\mathrm{P}<0.001)$. After septoplasty, $95 \%$ of patients showed improvement and only $5 \%$ still had persistent symptoms. The overall result of septoplasty, among the 20 patients, is given in Figure 4.

\section{DISCUSSION}

In this study considering 2 months, only 20 patients, undergoing septoplasty, were included the study. Among these DNS patients, three-fourth (75\%) were male and the remaining $(25 \%)$ were female. This report correlates with the study of Alotaibi et al., ${ }^{4}$. The mean age of the study subjects is 37.2 years. The majority are of age group $20-29$ years (45\%). This is similar to study subjects of Gandomi et al., ${ }^{7}$ where the mean age is 22.44 years. In study reports of Gandomi et al., ${ }^{7}$ young adults are benefited more from septoplasty. This may also be the reason for the high effectiveness of septoplasty in this current study.

To measure the symptoms seen in DNS patients, a validated screening tool called NOSE (Nasal Obstruction Symptom Evaluation) scale is commonly used. This is also used to evaluate the outcomes of septoplasty. NOSE scale is a valid, reliable and responsive instrument as given in Stewart et al., ${ }^{10}$ and Spiekermann et al., ${ }^{12}$. It is said to be well correlated with examination findings and computed tomography in study reports of Kahveci et al., ${ }^{8}$ and thus is a very useful tool to evaluate the effectiveness of pure septoplasty. In the current study, the NOSE score is taken preoperatively and postoperatively once for each patient. The postoperative NOSE score was taken 2 weeks after the surgery. Comparison of the degree of nasal symptoms before and after surgery helps to evaluate the septoplasty outcomes.

The NOSE scale used in this study, like said in Spiekermann et al., ${ }^{12}$, Stewart et al., ${ }^{9}$, Stewart et al., ${ }^{10}$, mainly measures five symptoms- nasal congestion, nasal obstruction, trouble to breathe through the nose, trouble to sleep, trouble while exercising or exertion. It is graded in the increasing order of severity from 0 to 4 . The scores are summed up for 20 . The mean and SD of preoperative NOSE score for 20 was 9.45 and 3.96. The mean and SD of postoperative NOSE score for 20 was 0.05 and 0.22 . $(\mathrm{P}<0.001)$

To assess the degree of obstruction, the total for 20 is graded on a scale of 100 and categorized as mild obstruction $(<25)$, moderate obstruction (25-50), severe obstruction $(>50)$. The study report of Alotaibi et al., ${ }^{4}$ assessed the NOSE scores likewise. Among the 20 study subjects, preoperatively obstruction was severe in $7(35 \%)$, moderate in $11(55 \%)$ and mild in $2(10 \%)$. Postoperatively obstruction was mild in $1(5 \%)$ and the remaining patients showed no symptoms. Improvement or complete relief was observed in 19 out of 20 patients in this study. This correlates with the reports of Alotaibi et al., ${ }^{4}$. On a scale of 100 , the mean and SD of the preoperative score was 47.25 and 19.83 , the mean and SD of the postoperative score was 0.25 and 1.11. $(\mathrm{P}<0.001)$

On the statistical analysis of the current study results, the $\mathrm{P}$ value is less than $0.001(\mathrm{P}<0.001)$. There is a significant difference before and after conducting septoplasty. Hence septoplasty is an effective intervention in the deviated nasal septum.

Though septoplasty is carried out as a common effective procedure for all DNS patients and showed improvement in quality of life as in reports of Bezerra et al., ${ }^{6}$ some tend to 
have remnant nasal symptoms. This correlates with reports of Chambers et al., ${ }^{5}$. But this current study corresponds with the results of Alotaibi et al.., , Gandomi et al., ${ }^{7}$, and Stewart et al., ${ }^{9}$, Samad et al., ${ }^{13}$ and Schwentner et al., ${ }^{14}$. Long term benefits of septoplasty may vary from person to person, with concordance to Konstantinidis et al., ${ }^{15}$. Overall, septoplasty is considered to be an effective procedure in many.

\section{CONCLUSION}

The definitive treatment of deviated nasal septum (DNS) is the universally accepted surgical correction or septoplasty. We developed the pre-and postoperative NOSE scale to prospectively and continuously monitor the results of septoplasty. There is also a substantial difference between preoperative scores inpatients and those seen in a normal population, indicating that the NOSE scale has useful discriminatory power. These findings indicate that the NOSE scale may be useful for short and long term quality control of nasal septal surgery and septoplasty resulted in a statistically significant improvement in the disease-specific NOSE scale.

\section{Conflict of Interests}

The authors declare that there is no conflict of interest.

\section{Funding information}

Self-funding

\section{Authors' Contribution}

Bala Ashwathy R M, who contributed to data collection, compiling and analysis of data, is the main author.

Dr. B C Surekha, who contributed to statistics and conclusions, is the corresponding author.

\section{ACKNOWLEDGEMENT}

Successful completion of any type of project requires help from several persons. Now, this is a little effort to show my deep gratitude to those helpful persons. I would like to express my gratitude to Dr. Shyam Sudhakar, Assistant professor, Department of E.N.T. Without his kind direction and proper guidance, this study would have been a little success. I would like to thank Dr. Ananthaeashwar V M, Assistant professor, Department of Community Medicine, for his help in statistical analysis. I am extremely grateful to him for providing such nice support.

\section{REFERENCES}

1. Moorthy PN, Kolloju S, Madhira S, Jowkar AB. Clinical study on the deviated nasal septum and its associated pathology. Int J Otolaryngol Head Neck Surg. 2014 Mar 10;2014.

2. Regmi R. Analysis of Symptoms and Types of Deviated Nasal Septum- A Clinical Study. Int J Health Allied Sci. 2018;4(1):2023.

3. Ajmal DM, Usman DN. Relation between chronic sinusitis and deviated nasal septum. Int J Sci Res Dent Med Sci. 2017;16(05):42-5.

4. Alotaibi A, Almutlaq BA. Post-surgical Outcomes of Patients Undertaken Septoplasty concerning Initial Clinical Complains. Res Otolaryngol. 2017;6(6):73-80.

5. Chambers KJ, Horstkotte KA, Shanley K, Lindsay RW. Evaluation of improvement in nasal obstruction following nasal valve correction in patients with a history of failed septoplasty. JAMA Facial Plast Surg. 2015 Sep 1;17(5):347-50.

6. Bezerra TF, Stewart MG, Fornazieri MA, Pilan RR, Pinna FD, Padua FG, et al. Quality of life assessment septoplasty in patients with nasal obstruction. Braz J Otorhinolaryngol. 2012 Jun;78(3):57-62.

7. Gandomi B, Bayat A, Kazemi T. Outcomes of septoplasty in young adults: the Nasal Obstruction Septoplasty Effectiveness study. Am J Otolaryngol. 2010 May 1;31(3):189-92.

8. Kahveci OK, Miman MC, Yucel A, Yucedag F, Okur E, Altuntas A. The efficiency of the Nose Obstruction Symptom Evaluation (NOSE) scale on patients with nasal septal deviation. Auris Nasus Larynx. 2012 Jun 1;39(3):275-9.

9. Stewart MG, Smith TL, Weaver EM, Witsell DL, Yueh B, Hannley MT, et al. Outcomes after nasal septoplasty: results from the Nasal Obstruction Septoplasty Effectiveness (NOSE) study. Otolaryngol Head Neck Surg. 2004 Mar;130(3):283-90.

10. Stewart MG, Witsell DL, Smith TL, Weaver EM, Yueh B, Hannley MT. Development and validation of the Nasal Obstruction Symptom Evaluation (NOSE) scale. Otolaryngol Head Neck Surg. 2004 Feb;130(2):157-63.

11. Rhee JS, Sullivan CD, Frank DO, Kimbell JS, Garcia GJ. A systematic review of patient-reported nasal obstruction scores: defining normative and symptomatic ranges in surgical patients. JAMA Facial Plast Surg. 2014 May 1;16(3):219-25.

12. Spiekermann C, Savvas E, Rudack C, Stenner M. Adaption and validation of the nasal obstruction symptom evaluation scale in German language (D-NOSE). Health Qual Life Outcomes. 2018 Dec;16(1):1-6.

13. Samad I, Stevens HE, Maloney A. The efficacy of nasal septal surgery. J Otolaryngol. 1992 Apr 1;21(2):88-91.

14. Schwentner I, Dejakum K, Schmutzhard J, Deibl M, Sprinzl GM. Does nasal septal surgery improve quality of life?. Acta Otolaryngol. 2006 Jul 1;126(7):752-7.

15. Konstantinidis I, Triaridis S, Triaridis A, Karagiannidis K, Kontzoglou G. Long term results following nasal septal surgery: focus on patients' satisfaction. Auris Nasus Larynx. 2005 Dec 1;32(4):369-74. 
Table 1: Nasal Obstruction Symptom Evaluation Scale

\begin{tabular}{lccccc} 
Symptoms & No problem & Very mild & Moderate & Fairly bad & Severe \\
Nasal stuffiness/congestion & 0 & 1 & 2 & 3 & 4 \\
Nasal obstruction/blockage & 0 & 1 & 2 & 3 & 4 \\
Trouble breathing through nose & 0 & 1 & 2 & 3 & 4 \\
$\begin{array}{l}\text { Trouble to sleep } \\
\begin{array}{l}\text { Unable to get enough air through my } \\
\text { nose during exercise or exertion }\end{array}\end{array}$ & 0 & 1 & 2 & 3 & 4 \\
\hline
\end{tabular}

A NOSE score of:

$<25$ is suggestive of Mild obstruction

25-50, is suggestive of moderate obstruction

$>50$ is suggestive of severe obstruction

Table 2: Symptom-wise and Age-wise (years) Distribution

\begin{tabular}{|c|c|c|c|c|c|c|c|c|c|}
\hline \multirow[t]{2}{*}{ Symptoms } & \multirow[t]{2}{*}{ Grade } & \multicolumn{4}{|c|}{ Preoperative } & \multicolumn{4}{|c|}{ Postoperative } \\
\hline & & 20-29 & 30-39 & $40-49$ & $\geq \mathbf{5 0}$ & $20-29$ & 30-39 & $40-49$ & $\geq 50$ \\
\hline \multirow{5}{*}{$\begin{array}{l}\text { Nasal congestion/ } \\
\text { stuffiness }\end{array}$} & o-no problem & - & - & - & - & 9 & 4 & 1 & 6 \\
\hline & 1-very mild & 2 & 3 & - & - & - & - & - & - \\
\hline & 2-moderate & 4 & 1 & - & 2 & - & - & - & - \\
\hline & 3-fairly bad & 3 & - & 1 & 2 & - & - & - & - \\
\hline & 4-severe & - & - & - & 2 & - & - & - & - \\
\hline \multirow{5}{*}{$\begin{array}{l}\text { Nasal obstruction/ } \\
\text { blockage }\end{array}$} & o-no problem & - & 2 & - & - & 9 & 4 & 1 & 6 \\
\hline & 1-very mild & 2 & 1 & - & - & - & - & - & - \\
\hline & 2-moderate & 4 & 1 & - & 2 & - & - & - & - \\
\hline & 3-fairly bad & 3 & - & 1 & 4 & - & - & - & - \\
\hline & 4-severe & - & - & - & - & - & - & - & - \\
\hline \multirow{5}{*}{$\begin{array}{l}\text { Trouble to breathe } \\
\text { through nose }\end{array}$} & o-no problem & 1 & 3 & - & - & 9 & 4 & 1 & 6 \\
\hline & 1-very mild & - & - & - & 1 & - & - & - & - \\
\hline & 2-moderate & 4 & - & - & 1 & - & - & - & - \\
\hline & 3-fairly bad & 4 & 1 & - & 1 & - & - & - & - \\
\hline & 4-severe & - & - & 1 & 3 & - & - & - & - \\
\hline \multirow{5}{*}{ Trouble to sleep } & o-no problem & 2 & - & - & - & 9 & 4 & 1 & 6 \\
\hline & 1-very mild & 4 & 2 & - & 1 & - & - & - & - \\
\hline & 2-moderate & 2 & - & 1 & 3 & - & - & - & - \\
\hline & 3-fairly bad & 1 & - & - & 1 & - & - & - & - \\
\hline & 4-severe & - & 2 & - & 1 & - & - & - & - \\
\hline \multirow{5}{*}{$\begin{array}{l}\text { Unable to get enough } \\
\text { air through nose while } \\
\text { exercise or exertion }\end{array}$} & o-no problem & 4 & 2 & - & - & 8 & 4 & 1 & 6 \\
\hline & 1-very mild & 4 & 2 & - & 1 & 1 & - & - & - \\
\hline & 2-moderate & 1 & - & 1 & 5 & - & - & - & - \\
\hline & 3-fairly bad & - & - & - & - & - & - & - & - \\
\hline & 4-severe & - & - & - & - & - & - & - & - \\
\hline
\end{tabular}

Table 3: Symptom-wise and Gender-wise Distribution

\begin{tabular}{|c|c|c|c|c|c|}
\hline \multirow[t]{2}{*}{ Symptom } & \multirow[t]{2}{*}{ Grade } & \multicolumn{2}{|l|}{ Male } & \multicolumn{2}{|l|}{ Female } \\
\hline & & Preoperative & Postoperative & Preoperative & Postoperative \\
\hline \multirow{5}{*}{$\begin{array}{l}\text { Nasal congestion or } \\
\text { stuffiness }\end{array}$} & o-no problem & - & 15 & - & 5 \\
\hline & 1-very mild & 1 & - & 4 & - \\
\hline & 2-moderate & 6 & - & 1 & - \\
\hline & 3-fairly bad & 6 & - & - & - \\
\hline & 4-severe & 2 & - & - & - \\
\hline
\end{tabular}


Table 3: (Continued)

\begin{tabular}{|c|c|c|c|c|c|}
\hline \multirow[t]{2}{*}{ Symptom } & \multirow[t]{2}{*}{ Grade } & \multicolumn{2}{|l|}{ Male } & \multicolumn{2}{|l|}{ Female } \\
\hline & & Preoperative & Postoperative & Preoperative & Postoperative \\
\hline \multirow{5}{*}{$\begin{array}{l}\text { Nasal obstruction or } \\
\text { blockage }\end{array}$} & o-no problem & - & 15 & 2 & 5 \\
\hline & 1-very mild & 1 & - & 2 & - \\
\hline & 2-moderate & 6 & - & 1 & - \\
\hline & 3-fairly bad & 8 & - & - & - \\
\hline & 4-severe & - & - & - & - \\
\hline \multirow{5}{*}{$\begin{array}{l}\text { Trouble to breathe } \\
\text { through nose }\end{array}$} & o-no problem & - & 15 & 4 & 5 \\
\hline & 1-very mild & - & - & 1 & - \\
\hline & 2-moderate & 5 & - & - & - \\
\hline & 3-fairly bad & 6 & - & - & - \\
\hline & 4-severe & 4 & - & - & - \\
\hline \multirow[t]{5}{*}{ Trouble to sleep } & o-no problem & 2 & 15 & - & 5 \\
\hline & 1-very mild & 5 & - & 2 & - \\
\hline & 2-moderate & 5 & - & 1 & - \\
\hline & 3-fairly bad & 2 & - & - & - \\
\hline & 4-severe & 1 & - & 2 & - \\
\hline \multirow{5}{*}{$\begin{array}{l}\text { Unable to get enough air } \\
\text { through nose while exer- } \\
\text { cise or exertion }\end{array}$} & o-no problem & 4 & 14 & 2 & 5 \\
\hline & 1-very mild & 5 & 1 & 2 & - \\
\hline & 2-moderate & 6 & - & 1 & - \\
\hline & 3-fairly bad & - & - & - & - \\
\hline & 4-severe & - & - & - & - \\
\hline
\end{tabular}

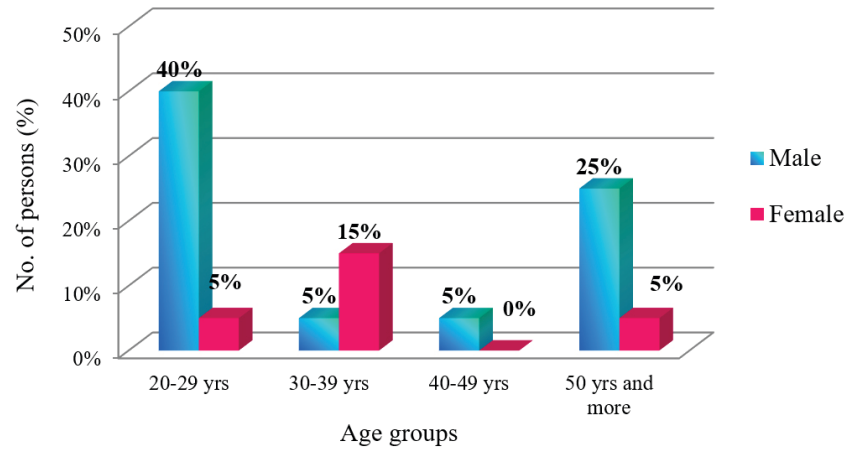

Figure 1: Age and Gender wise distribution of patients undergoing septoplasty

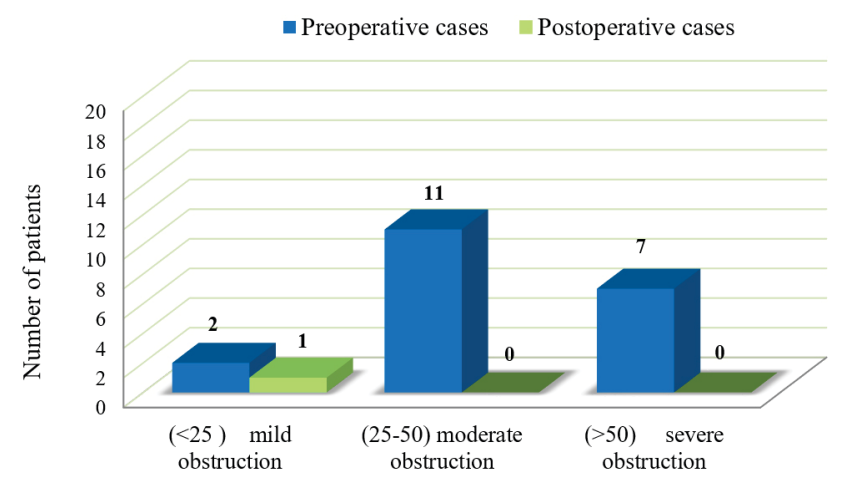

Figure 2: Grading the NOSE scores on the scale of 100.

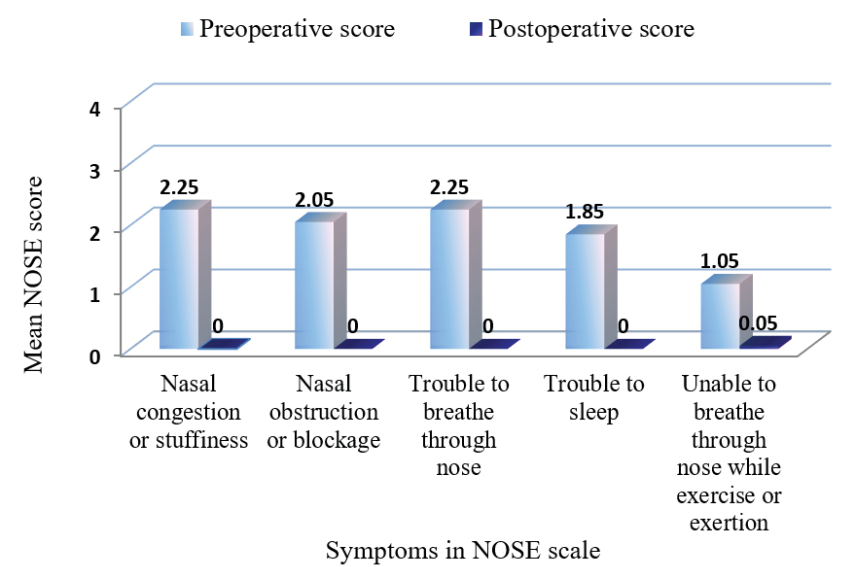

Figure 3: Comparison of preoperative and postoperative NOSE scores.

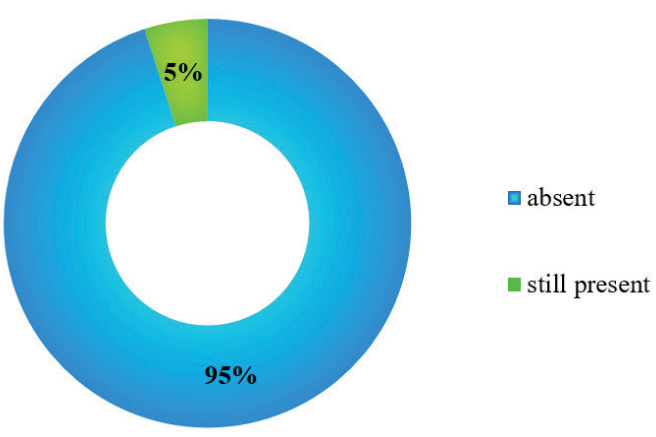

Figure 4: Nasal obstruction in patients after septoplasty. 